\title{
Pengembangan Media Pembelajaran Interaktif tentang Optika Berbasis Android Menggunakan Perangkat Lunak Ispring Suite 7.0 untuk Mahasiswa S-1 Pendidikan Fisika pada Pokok Bahasan Interferensi Cahaya
}

\author{
Elfira Yulia Sasahan, Raden Oktova, Oky Oktavia I.R.N. ${ }^{1}$ \\ Program Studi Pendidikan Fisika, Fakultas Keguruan dan Ilmu Pendidikan \\ Universitas Ahmad Dahlan \\ Kampus III, Jl. Prof. Dr. Soepomo, Yogyakarta 55164 \\ ${ }^{1}$ Email: okyoktaviaindri@gmail.com
}

\begin{abstract}
Light interference in the course Optics at undergraduate Physics Education is an abstract subject, and students need a practical, interactive medium for learning independently the material already given in lectures by the lecturer, especially for problem solving exercise. Therefore a study has been performed to develop an android-based interactive learning medium on light interference in Indonesian using the software Ispring Suite 7.0. The study was based on the ADDIE development model, which includes the steps: analysis, design, development, implementation, and evaluation. The feasibility of the medium was validated using questionnaires by subject experts, media (IT) experts, and students as users. The feasibility level of the medium given by the subject experts, the media experts, and the students are, respectively, $87.94 \%$, $90.44 \%$, dan $87.99 \%$. It is concluded that the medium developed is highly feasible for independent learning.
\end{abstract}

Keywords: interactive learning medium, android, Optics, light interference, Ispring Suite

\begin{abstract}
Abstrak: Pokok bahasan interferensi cahaya dalam mata kuliah Optika S-1 Pendidikan Fisika bersifat abstrak, dan mahasiswa memerlukan media interaktif yang praktis untuk belajar secara mandiri materi yang diberikan dosen dalam tatap muka, terutama untuk berlatih soal secara mandiri. Oleh karena itu dilakukan penelitian untuk mengembangkan media pembelajaran tentang interferensi cahaya berbasis android dalam bahasa Indonesia dengan menggunakan perangkat lunak Ispring Suite 7.0. Penelitian ini dilakukan dengan model pengembangan ADDIE, yang meliputi langkah-langkah: analysis (analisis), design (desain), development (pengembangan), implementation (implementasi), dan evaluation (evaluasi). Untuk mengetahui kelayakan media dilakukan validasi melalui angket oleh ahli media (TI), ahli materi, dan pengguna mahasiswa. Tingkat kelayakan media yang diberikan oleh ahli materi, ahli media dan pengguna berturut-turut adalah sebesar 87,94 \%, 90,44 \%, dan 87,99 \%. Dapat disimpulkan bahwa media yang dikembangkan sangat layak digunakan sebagai sumber belajar mandiri.
\end{abstract}

Kata kunci: media pembelajaran interaktif, android, Optika, interferensi cahaya, Ispring Suite

\section{PENDAHULUAN}

Mata kuliah Optika merupakan salah satu mata kuliah wajib pada program studi S-1 Pendidikan Fisika, Universitas Ahmad Dahlan. Materinya meliputi optika geometris dan optika fisis. Optika fisis antara lain membahas interferensi cahaya, yaitu perpaduan dua atau lebih sumber cahaya sehingga menghasilkan titik-titik dengan intensitas yang lebih terang dan yang lebih gelap. Suatu pola interferensi teramati jika sumber-sumbernya koheren dengan panjang gelombang yang sama (Serway \& Jewett, 2010:117-140). Pokok bahasan interferensi cahaya dikaji dalam penelitian ini karena dianggap bersifat abstrak dan mahasiswa 
memerlukan media interaktif yang praktis untuk mempelajari secara mandiri materi yang diberikan dosen dalam tatap muka, terutama untuk berlatih soal secara mandiri.

Media pembelajaran interaktif merupakan media penyampaian pesan antara tenaga pendidik kepada peserta didik yang memungkinkan komunikasi antara manusia dan teknologi melalui sistem dan infrastruktur berupa program aplikasi serta pemanfaatan media elektronik sebagai bagian dari metode edukasinya, melalui media pembelajaran interaktif proses belajar dapat dilakukan di mana saja dan kapan saja. Media pembelajaran dapat dirangsang sedemikian rupa sehingga peserta didik dapat melakukan kegiatan belajar dengan leluasa di manapun dan kapanpun tanpa berggantung pada seorang pendidik (Arsyad, 2013). Cara belajar ini dikenal sebagai mobile learning, disingkat m-learning (Georgiev, dkk., 2004).

Hamzah (2009) dalam penelitiannya tentang m-learning menyimpulkan bahwa m-learning telah mulai memainkan peranan penting dalam pendidikan. Eksistensi $m$-learning dan piranti nirkabel (wireless devices) telah menjadi suatu kenyataan. Kebebasan peserta didik untuk belajar dan mendapat informasi menjadikan m-learning lebih disukai. Dari waktu ke waktu, cacah pengguna telepon pintar (smartphone) android semakin meningkat pesat, karena kecanggihan fitur-fiturnya, hargannya yang relatif murah, dukungan aplikasi yang sangat luas. Android merupakan sistem operasi yang berbasis Linux untuk telepon seluler seperti telepon pintar dan komputer tablet (Salbino, 2014).

Berdasarkan hasil observasi dan wawancara kepada mahasiswa Pendidikan Fisika, dalam proses perkuliahan media pembelajaran yang sering digunakan untuk menunjang proses pembelajaran berupa media presentasi Microsoft Powerpoint yang kurang menarik dan tidak interaktif, sehingga mahasiswa merasa sulit memahami materi yang telah dijelaskan. Mahasiswa perlu mempelajari kembali materi yang telah dijelaskan di luar perkuliahan agar dapat memahami materi tersebut. Sebagian besar mahasiswa adalah pengguna android, tetapi rata-rata penggunaan android hanya sebatas untuk game dan social media. Android belum dimanfaatkan untuk pembelajaran fisika.

Salah satu alternatif untuk mengatasi permasalahan ini yaitu dengan penggunaan media pembelajaran interaktif berbasis android dengan menggunakan perangkat lunak Ispring Suite, yaitu salah satu tool yang terintegrasi dengan Microsoft Powerpoint, dapat di-publish dalam bentuk HTML dan dapat dijalankan pada perangkat android dengan perangkat lunak Intel XDK (Charmonman, dkk., 2015). Di Indonesia, pengembangan media pembelajaran fisika dengan Ispring Suite dipublikasikan baru-baru ini oleh Febrianti, dkk. (2017) berupa modul yang dibuat dengan Ispring Suite 6 berbasis discovery learning pada pokok bahasan kinematika gerak lurus untuk SMA Kelas X. Penelitian sebelumnya dilakukan oleh Astra dkk. (2015) untuk mengembangkan media berbasis android untuk SMA tentang teori kinetik gas.

Berdasarkan latar belakang tersebut peneliti mengembangkan media pembelajaran interaktif tentang Optika berbasis android menggunakan perangkat lunak Ispring Suite 7 untuk mahasiswa S-1 Pendidikan Fisika pada pokok bahasan Interferensi Cahaya. Media pembelajaran interaktif ini diharapkan dapat membantu mahasiswa dalam mempelajari pokok bahasan Interferensi Cahaya yang bersifat abstrak dan dapat dipelajari secara mandiri di mana saja dan kapan saja. Masalah yang diteliti adalah berapakah tingkat kelayakan media yang dikembangkan.

\section{METODE PENELITIAN}

Penelitian ini menggunakan model pengembangan ADDIE, dengan tahap-tahap analisis, desain, development, implementation dan evaluasi (Aldoobie, 2015, Muruganantham, 2015). 
Ispring Suite 7 merupakan salah satu tool yang terintegrasi dengan Micsrosoft Powerpoint. Setelah selesai dibuat, media di-publish dalam bentuk HTML dan selanjutnya agar bisa dijalankan pada perangkat android digunakan perangkan lunak Intel XDK. Selain itu juga digunakan perangkat lunak Benetton GIF serta CorelDraw. Adapun perangkat keras yang digunakan adalah laptop, kabel data, dan telepon pintar android minimal versi 5.0.

Pada tahap pengembangan diperhatikan kesesuaian antara bagian-bagian materi, animasi, video dan evaluasi yang ditampilkan untuk mempermudah mahasiswa dalam memahami materi. Agar media pembelajaran menjadi lebih menarik, diperhatikan juga tampilan dan kesesuaian tema pada media pembelajaran tersebut. Pada tahap ini dilakukan review atau validasi dari para ahli, yaitu dua orang dosen sebagai ahli media (Teknologi Informasi), dan dua orang dosen yang berpengalaman mengajar pokok bahasan Interferensi Cahaya sebagai ahli materi. Selanjutnya pada tahap implementasi, media yang sudah dibuat dan direvisi selanjutnya diujicobakan kepada pengguna berupa 11 orang mahasiswa Pendidikan Fisika. Tahap evaluasi merupakan tahap akhir penelitian. Ketercapaian tujuan penelitian diukur dan diketahui melalui analisis data, dengan demikian dapat diketahui tingkat kelayakan media pembelajaran interaktif yang dibuat.

Instrumen penelitian yang digunakan dalam pengembangan media pembelajaran ini berupa angket dengan skala Likert (Barua, 2013, Croasmun dan Ostrom, 2011), yaitu meliputi empat tingkat penilaian: Sangat Baik $=4$, Baik $=3$, Kurang $=2$, Sangat Kurang $=1$, dan disusun dalam bentuk daftar bentuk pernyataan dan diikuti oleh empat respon dengan tingkatan Sangat Setuju (SS), Setuju (S), Tidak Setuju (TS), Sangat Tidak Setuju (STS). Tingkat kelayakan media, $P$ dihitung dengan persamaan

$$
P=\frac{\text { skor hasil penilaian }}{\text { skor maksimum }} \times 100 \% \text {. }
$$

Persentase yang telah diperoleh kemudian ditransformasikan ke dalam kalimat yang bersifat kualitatif. Untuk menentukan kriteria kualitatif (sangat layak, layak, kurang layak dan tidak layak) digunakan klasifikasi seperti disajikan pada Tabel 1 (Sari dan Oktova, 2010). Media dikatakan layak untuk digunakan apabila dari angket diperoleh hasil yang berada pada rentang 76\% - 100\% atau 51\% - 75\%, atau pada kriteria "sangat layak" atau "layak".

Tabel 1. Interval nilai dan klasifikasi tingkat kelayakan media

\begin{tabular}{cll}
\hline No. & Inteval Nilai, $\boldsymbol{P}$ & Tingkat Kelayakan \\
\hline 1. & $76-100 \%$ & Sangat Layak \\
2. & $51-75 \%$ & Layak \\
3. & $26-50 \%$ & Kurang Layak \\
4. & $0-25 \%$ & Tidak Layak \\
\hline
\end{tabular}

\section{HASIL DAN PEMBAHASAN}

Setelah dilakukan beberapa tahapan dalam perancangan dan pengembangan media pembelajaran, penelitian ini menghasilkan produk sebuah media pembelajaran interaktif tentang Optika berbasis android untuk mahasiswa S-1 Pendidikan Fisika pada pokok bahasan Intereferensi Cahaya.

Dalam media pembelajaran ini terdapat beberapa tampilan, di antaranya yaitu tampilan awal, tampilan menu, tampilan isi materi, dan dapat dilihat berturut-turut pada Gambar 1(a), (b) dan (c). 

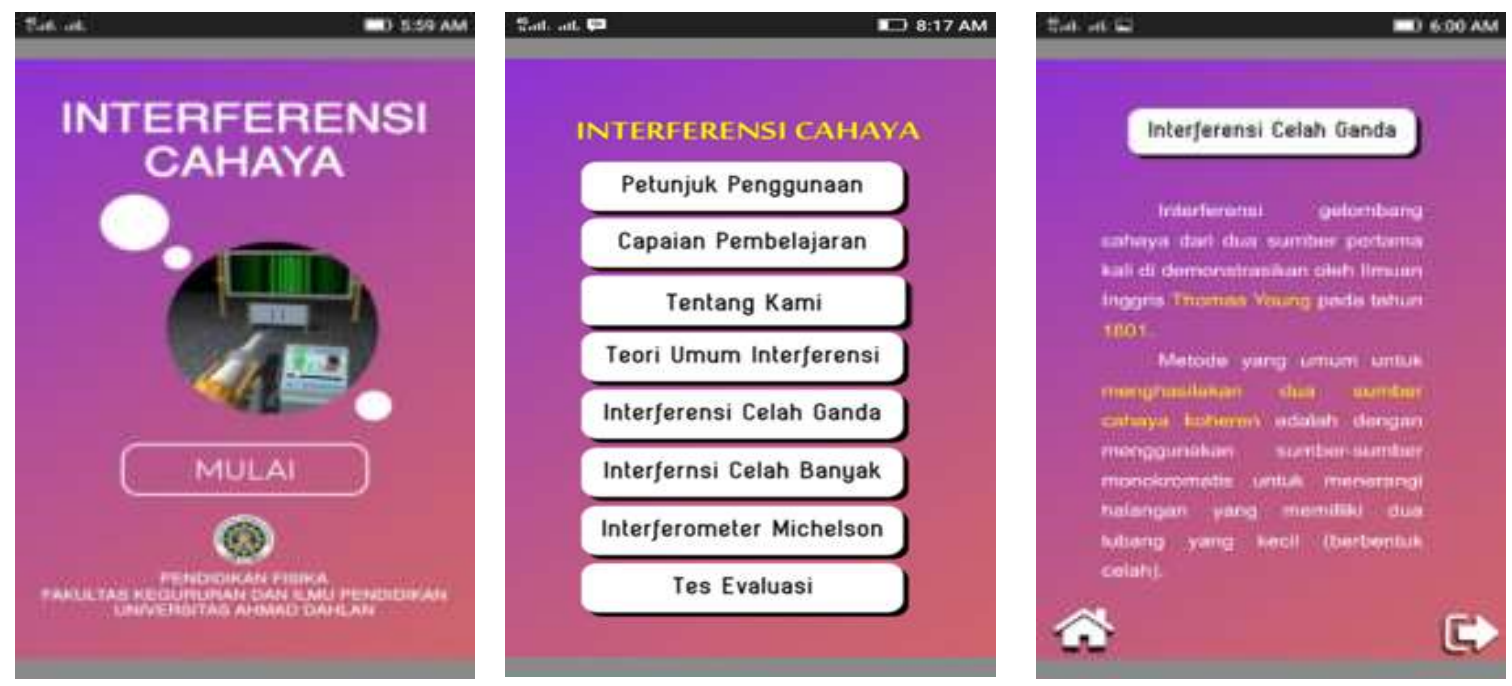

Gambar 1. Tampilan dalam media yang dikembangkan: (a) tampilan awal, (b) tampilan menu, dan (c) tampilan isi materi

Tabel 2 menyajikan hasil penilaian uji kelayakan oleh dua orang dosen sebagai ahli materi. Dalam hal sebaran nilai antara kedua ahli materi, secara umum nilai yang diberikan cukup kecil, mulai dari 0 hingga 14,3\%, kecuali untuk butir 3 tentang "Notasi persamaan dan lambang-lambang besaran fisika dalam media pembelajaran sesuai dengan yang digunakan dalam perkuliahan" deviasi rata-ratanya $20 \%$ dari nilai rata-rata. Menarik untuk dicermati bahwa dalam sebagian besar aspek kedua ahli memberikan nilai yang sama sehingga deviasi rata-rata sama dengan nol, yaitu untuk butir 1, 2, 4, 5, 6, 9, 15, 16, 17, 18, 22, 23, 24, 25, 26, 27 dan 28. Selain itu, ternyata kedua ahli materi cenderung memberikan nilai yang tinggi (34), kecuali untuk butir 3 (yang sudah disebut di muka) nilai rata-ratanya 2,5. Jika dirata-rata secara keseluruhan, diperoleh tingkat kelayakan media yang dikembangkan menurut penilaian ahli materi sebesar 87,94\%. Berdasarkan klasifikasi tingkat kelayakan materi menurut Tabel 1, dapat disimpulkan bahwa dari aspek materi, media yang dikembangkan sangat layak digunakan sebagai sumber belajar mandiri.

Tabel 2. Hasil penilaian uji kelayakan oleh ahli materi

\begin{tabular}{|c|c|c|c|c|}
\hline \multirow[t]{2}{*}{ No } & \multirow[t]{2}{*}{ Pertanyaan } & \multicolumn{3}{|c|}{ Nilai } \\
\hline & & Ahli 1 & Ahli 2 & Rata-rata \\
\hline 1 & $\begin{array}{l}\text { Materi dalam media pembelajaran sesuai } \\
\text { dengan capaian pembelajaran. }\end{array}$ & 4 & 4 & 4,0 \\
\hline 2 & $\begin{array}{l}\text { Materi dalam media pembelajaran sesuai } \\
\text { dengan indikator. }\end{array}$ & 4 & 4 & 4,0 \\
\hline 3 & $\begin{array}{l}\text { Notasi persamaan dan lambang-lambang } \\
\text { besaran fisika dalam media pembelajaran } \\
\text { sesuai dengan yang digunakan dalam } \\
\text { perkuliahan. }\end{array}$ & 3 & 2 & 2,5 \\
\hline 4 & $\begin{array}{l}\text { Materi dalam media pembelajaran memiliki } \\
\text { konsep yang benar. }\end{array}$ & 3 & 3 & 3,0 \\
\hline 5 & $\begin{array}{l}\text { Media pembelajaran menyajikan materi secara } \\
\text { lengkap. }\end{array}$ & 3 & 3 & 3,0 \\
\hline
\end{tabular}


6 Materi yang disajikan dalam media pembelajaran diuraiakan secara jelas.

7 Penyajian materi dalam media pembelajaran disampaikan secara runtut.

8 Gambar sesuai dengan materi yang terdapat dalam media pembelajaran.

9 Video sesuai dengan materi yang terdapat dalam media pembelajaran.

10 Contoh soal sesuai dengan materi yang terdapat dalam media pembelajaran.

11 Penyelesaian contoh soal sesuai dengan materi yang terdapat dalam media pembelajaran.

12 Soal evaluasi sesuai dengan materi yang terdapat dalam media pembelajaran.

13 Materi dalam media pembelajaran disajikan dengan bahasa yang mudah untuk dipahami sesuai usia peserta didik (mahasiswa).

14 Materi dalam media pembelajaran disajikan sesuai dengan EYD (Ejaan Yang Disempurnakan).

15 Materi dalam media pembelajaran disajikan dengan kalimat yang tidak menimbulkan penafsiran ganda.

16 Contoh soal dalam media pembelajaran disajikan sesuai dengan EYD (Ejaan Yang Disempurnakan).

17 Contoh soal dalam media pembelajaran disajikan dengan bahasa yang mudah untuk dipahami sesuai usia peserta didik (mahasiswa).

18 Contoh soal dalam media pembelajaran disajikan dengan kalimat yang tidak menimbulkan penafsiran ganda.

19 Soal evaluasi dalam media pembelajaran disajikan dengan bahasa yang mudah untuk dipahami sesuai usia peserta didik (mahasiswa).

20 Soal evaluasi dalam media pembelajaran disajikan sesuai dengan EYD (Ejaan Yang Disempurnakan).

21 Soal evaluasi dalam media pembelajaran disajikan dengan kalimat yang tidak menimbulkan penafsiran ganda.

22 Materi yang disajikan dalam media pembelajaran membantu mahasiswa untuk mencapai capaian pembelajaran.

23 Contoh soal dalam media pembelajaran membantu mahasiswa dalam memahami 
materi.

24 Video dalam media pembelajaran membantu mahasiswa dalam memahami materi.

25 Media pembelajaran dapat dijadikan sumber belajar mandiri.

26 Materi dalam media pembelajaran disajikan dengan ringkas.

27 Media pembelajaran bersifat portable (mudah dibawa).

28 Video dalam media pembelajaran mudah untuk dioperasikan.

$\begin{array}{lll}4 & 4 & 4,0 \\ 4 & 4 & 4,0 \\ 4 & 4 & 4,0 \\ 4 & 4 & 4,0 \\ 4 & 4 & 4,0\end{array}$

Tabel 3 menyajikan hasil penilaian uji kelayakan oleh dua orang dosen sebagai ahli media. Dalam hal sebaran nilai antara kedua ahli media, secara umum nilai yang diberikan cukup kecil, mulai dari 0 hingga 14,3\%. Menarik untuk dicermati bahwa dalam banyak aspek kedua ahli memberikan nilai yang sama sehingga deviasi rata-rata sama dengan nol, yaitu untuk butir 1, 2, 6, 10, 11, 13, 14, 16, dan 17. Selain itu, ternyata kedua ahli media cenderung memberikan nilai yang tinggi (3-4), dengan sebagian besar aspek nilai rata-rata per butir sebesar 3,5 - 4. Jika dirata-rata secara keseluruhan, diperoleh tingkat kelayakan media yang dikembangkan menurut penilaian ahli media sebesar 90,44\%. Berdasarkan klasifikasi tingkat kelayakan media menurut Tabel 1, dapat disimpulkan bahwa dari aspek media atau TI, media yang dikembangkan sangat layak digunakan sebagai sumber belajar mandiri.

Tabel 3. Hasil penilaian uji kelayakan oleh ahli media

\begin{tabular}{clccc}
\hline No. & \multicolumn{1}{c}{ Pertanyaan } & \multicolumn{3}{c}{ Nilai } \\
\cline { 2 - 5 } & Ahli 1 & Ahli 2 & Rata-rata \\
\hline 1 & $\begin{array}{l}\text { Desain tampilan utama dalam media } \\
\text { pembelajaran menarik. }\end{array}$ & 4 & 4,0 \\
2 & $\begin{array}{l}\text { Kombinasi warna dalam media } \\
\text { pembelajaran memiliki tampilan yang } \\
\text { menarik. }\end{array}$ & 4 & 4 & 4,0 \\
3 & $\begin{array}{l}\text { Pemilihan jenis huruf membuat } \\
\text { tampilan media pembelajaran menarik. }\end{array}$ & 3 & 4 & 3,5 \\
4 & $\begin{array}{l}\text { Pemilihan warna huruf membuat } \\
\text { tampilan media pembelajaran menarik. }\end{array}$ & 4 & 3 & 3,5 \\
5 & $\begin{array}{l}\text { Pemilihan ukuran huruf membuat } \\
\text { tampilan media pembelajaran menarik. }\end{array}$ & 4 & 3 & 3,5 \\
6 & $\begin{array}{l}\text { Desain tampilan isi dalam media } \\
\text { pembelajaran disajikan dengan menarik. }\end{array}$ & 4 & 4 & 4,0 \\
7 & $\begin{array}{l}\text { Video yang disajikan dalam media } \\
\text { pembelajaran menarik. }\end{array}$ & 3 & 3 & 3,0 \\
8 & $\begin{array}{l}\text { Media pembelajaran dapat dijadikan } \\
\text { sumber belajar mandiri. }\end{array}$ & 3 & 4 & 3,5 \\
9 & $\begin{array}{l}\text { Media pembelajaram dapat dijadikan } \\
\text { sumplemen pembelajaran mandiri. }\end{array}$ & 3 & 4 & 3,5 \\
$\begin{array}{l}\text { Media pembelajaran memiliki tombol- } \\
\text { tombol yang dapat digunakan dengan } \\
\text { mudah. }\end{array}$ & 3 & 3 & 3,0 \\
\hline
\end{tabular}




\begin{tabular}{cllll}
\hline 11 & $\begin{array}{l}\text { Soal evaluasi yang disajikan dalam } \\
\text { media pembelajaran bersifat interaktif } \\
\text { dengan pengguna. }\end{array}$ & 4 & 4 & 4,0 \\
12 & $\begin{array}{l}\text { Video yang disajikan dalam media } \\
\text { pembelajaran mudah digunakan. }\end{array}$ & 3 & 4 & 3,5 \\
13 & $\begin{array}{l}\text { Pedoman penggunaan media } \\
\text { pembelajaran disajikan dengan jelas. }\end{array}$ & 3 & 3 & 3,0 \\
14 & $\begin{array}{l}\text { Media pembelajaran bersifat portable } \\
\text { (mudah dibawa). media pembelajaran }\end{array}$ & 4 & 4 & 4,0 \\
15 & $\begin{array}{l}\text { Materi dalam media pisajikan dengan ringkas. } \\
\text { Link (tautan) dalam media } \\
\text { pembelajaran mudah untuk digunakan. }\end{array}$ & 4 & 4 & 3,5 \\
17 & $\begin{array}{l}\text { Video dalam media pembelajaran } \\
\text { mudah dioperasikan. }\end{array}$ & 4 & 4 & 4,0 \\
\hline
\end{tabular}

Hasil penilaian uji kelayakan penggunaan oleh pengguna disajikan pada Tabel 4. Kolom ke-3 Tabel 4 adalah rata-rata dan deviasi standard per aspek dari 11 mahasiswa penilai. Di sini digunakan ukuran sebaran berupa deviasi standard (bukan deviasi rata-rata seperti pada penilaian ahli materi dan ahli media), karena cacah mahasiswa cukup banyak, yaitu 11 orang. Sebagaimana terlihat dari Tabel 4, pada penilaian per aspek tidak terdapat nilai yangq sama, dengan kata lain tidak ada deviasi standard sama dengan nol; hal ini merupakan indikasi bahwa para mahasiswa mempunyai penilaian yang cukup bervariasi dan bebas (independen) satu sama lain. Walaupun demikian, deviasi standard nilai per aspek cukup kecil, umumnya sekitar 10\%, kecuali aspek ke-3 "Desain tampilan awal dalam media pembelajaran menarik" yang mempunyai deviasi standard cukup besar sekitar 18,9\%. Semua nilai per aspek menunjukkan tingkat kelayakan lebih dari $75 \%$ atau dengan kata lain para mahasiswa memberikan nilai "sangat layak" pada semua aspek, dan rata-rata berbobot dari seluruh aspek memberikan tingkat kelayakan sebesar 87,99\%.

Tabel 4. Hasil penilaian uji kelayakan oleh pengguna

\begin{tabular}{clc}
\hline No. & \multicolumn{1}{c}{ Pernyataan } & \multicolumn{1}{c}{ Nilai } \\
\hline 1 & $\begin{array}{l}\text { Gambar-gambar dalam media pembelajaran dapat } \\
\text { memperjelas materi yang disampaikan. }\end{array}$ & $3,64 \pm 0,50$ \\
2 & $\begin{array}{l}\text { Materi (teori) dalam media pembelajaran sesuai dengan } \\
\text { capaian pembelajaran. }\end{array}$ & $3,55 \pm 0,52$ \\
3 & $\begin{array}{l}\text { Desain tampilan awal dalam media pembelajaran } \\
\text { menarik. }\end{array}$ & $3,18 \pm 0,60$ \\
4 & $\begin{array}{l}\text { Desain tampilan isi dalam media pembelajaran } \\
\text { disajikan dengan menarik. }\end{array}$ & $3,55 \pm 0,52$ \\
5 & $\begin{array}{l}\text { Kombinasi warna dalam media pembelajaran menarik. } \\
6\end{array}$ & $\begin{array}{l}\text { Tata letak judul, teks dan gambar dan persamaan- } \\
\text { persamaan dalam media pembelajaran disusun dengan } \\
\text { teratur. }\end{array}$ \\
7 & $\begin{array}{l}\text { Proporsi ukuran huruf dalam media pembelajaran } \\
\text { sesuai dengan ukuran media. }\end{array}$ & $3,54 \pm 0,56$ \\
& \multicolumn{2}{l}{$3,64 \pm 0,50$} \\
\hline
\end{tabular}




\begin{tabular}{|c|c|c|}
\hline 8 & $\begin{array}{l}\text { Pemilihan jenis huruf membuat tampilan media } \\
\text { pembelajaran menarik. }\end{array}$ & $3,73 \pm 0,47$ \\
\hline 9 & $\begin{array}{l}\text { Pemilihan warna huruf membuat tampilan media } \\
\text { pembelajaran menarik. }\end{array}$ & $3,64 \pm 0,50$ \\
\hline 10 & Vidio yang disajikan dalam pembelajaran menarik. & $3,36 \pm 0,50$ \\
\hline 11 & $\begin{array}{l}\text { Soal evaluasi yang disajikan dalam media pembelajaran } \\
\text { bersifat interaktif dengan pengguna. }\end{array}$ & $3,36 \pm 0,50$ \\
\hline 12 & $\begin{array}{l}\text { Vidio yang disajikan dalam media pembelajaran mudah } \\
\text { digunakan. }\end{array}$ & $3,36 \pm 0,50$ \\
\hline 13 & $\begin{array}{l}\text { Materi (teori) dalam media pembelajaran dapat } \\
\text { mempermudah mahasiswa dalam belajar. }\end{array}$ & $3,45 \pm 0,52$ \\
\hline 14 & $\begin{array}{l}\text { Media pembelajaran dapat disajikan sumber belajar } \\
\text { mandiri. }\end{array}$ & $3,63 \pm 0,50$ \\
\hline 15 & $\begin{array}{l}\text { Materi (teori) dalam media pembelajaran disajikan } \\
\text { dengan bahaasa yang mudah saya pahami. }\end{array}$ & $3,45 \pm 0,52$ \\
\hline 16 & $\begin{array}{l}\text { Contoh soal dan penyelesaian dalam media } \\
\text { pembelajaran disajikan dengan bahasa yang mudah } \\
\text { saya pahami. }\end{array}$ & $3,45 \pm 0,52$ \\
\hline 17 & $\begin{array}{l}\text { Evaluasi dalam media pembelajaran disajikan dengan } \\
\text { bahasa yang mudah saya pahami. }\end{array}$ & $3,54 \pm 0,52$ \\
\hline 18 & $\begin{array}{l}\text { Pedoman penggunaan media pembelajaran disajikan } \\
\text { dengan jelas. }\end{array}$ & $3,64 \pm 0,50$ \\
\hline 19 & $\begin{array}{l}\text { Materi (teori) dalam media pembelajaran disajikan } \\
\text { dengan ringkas. }\end{array}$ & $3,27 \pm 0,47$ \\
\hline 20 & Media pembelajaran mudah dioperasikan. & $3,73 \pm 0,47$ \\
\hline 21 & $\begin{array}{l}\text { Media pembelajaran berifat portable (mudah dibawa } \\
\text { kemana-mana). }\end{array}$ & $3,82 \pm 0,40$ \\
\hline
\end{tabular}

Tabel 5. Rekapitulasi tingkat kelayakan media

\begin{tabular}{cccc}
\hline No. & Validator & Tingkat Kelayakan (\%) & Kriteria \\
\hline 1 & Ahli Materi & 87,94 & Sangat Layak \\
2 & Ahli Media & 90,44 & Sangat Layak \\
3 & Pengguna & 87,99 & Sangat Layak \\
\hline
\end{tabular}

Tabel 5 menyajikan rekapitulasi tingkat kelayakan media yang dikembangkan menurut penilaian ahli materi, ahli media dan pengguna, yaitu berturut-turut sebesar 87,94\%, 90,44 $\%$, dan 87,99 \%. Berdasarkan klasifikasi tingkat kelayakan media menurut Tabel 1, dapat disimpulkan bahwa media yang dikembangkan sangat layak digunakan sebagai sumber belajar mandiri. 
Keterbatasan utama media ini adalah, pengoperasiannya hanya bisa dilakukan pada telepon pintar dengan sistem operasi andoid minimal versi 5.0. Mengingat dalam prakteknya mahasiswa juga menggunakan telepon pintar dengan berbagai sistem operasi, bukan hanya android, untuk penelitian selanjutnya dapat digunakan sistem operasi lain selain android. Selain itu, saat ini sudah tersedia Ispring Suite yang lebih baru, yaitu versi 8.0, sehingga untuk penelitian selanjutnya dapat digunakan Ispring Suite versi 8.0.

\section{KESIMPULAN DAN SARAN}

\subsection{Kesimpulan}

- Tingkat kelayakan media yang diberikan oleh ahli materi, ahli media dan pengguna berturut-turut adalah sebesar 87,94\%, 90,44\%, dan 87,99\%. Dapat disimpulkan bahwa media yang dikembangkan layak digunakan sebagai sumber belajar mandiri. Keterbatasan media ini adalah, pengoperasiannya hanya bisa dilakukan pada telepon pintar dengan sistem operasi andoid minimal versi 5.0.

\subsection{Saran}

Untuk penelitian selanjutnya dapat dikembangkan media pembelajaran fisika dengan menggunakan perangkat lunak Ispring Suite versi baru 8.0 untuk digunakan pada telepon pintar dengan sistem operasi lain selain android.

\section{DAFTAR PUSTAKA}

Aldoobie, N. (2015). ADDIE Model. American International Journal of Contemporary Research, 5(6), 68-72. www.aijcrnet.com/journals/Vol_5_No_6_December_2015/10.pdf

Arsyad, A. (2013). Media Pembelajaran. Jakarta: Rajawali Press.

Astra, I.M., Nasbey, H. \& Nugraha, A. (2015). The aim of this research is to create learning media for senior high school students through an android application in the form of a simulation lab. Eurasia Journal of Mathematics, Science \& Technology Education, 11(5), 1081-1088. doi:10.12973/eurasia.2015.1376a

Barua, A., 2013, "Methods for decision-making in survey questionnaires based on Likert scale", Journal of Asian Scientific Research, 3(1), 35-38.

Charmonman, S., Mongkhonvanit, P., \& Kim, M.-J. (2015). A Survey of Apps for E-Learning 2015. The Twelfth International Conference on eLearning for Knowledge-Based Society, 11-12 December 2015, Thailand, 49.1-49.4.

Croasmun, J.T., dan Ostrom, L., 2011, "Using Likert-type scales in the social sciences", Journal of Adult Education, 40(1), 19-22.

Febrianti, K. V., Bakri, F., \& Nasbey, H. (2017). Pengembangan Modul Digital Fisika Berbasis Discovery Learning pada Pokok Bahasan Kinematika Gerak Lurus. Jurnal Wahana Pendidikan Fisika, 2(2), 18-26.

Georgiev, T., Georgiva, E., Smirakov, A. (2004). M-Learning: A New Stage of E-Learning. Proceedings International conference on computer system and technologies.

Hamzah, M. b. (2009). Mobile Learning: New Era in Malaysia. Jurnal Pendidikan Dasar, 10(2), 153-156.

Muruganantham, G. (2015). Developing of E-content Package by using ADDIE Model. 
International Journal of Applied Research, 1(3), 52-54.

www.allresearchjournal.com/archives/2015/vol1issue3/PartB/67.1.pdf

Salbino, S. (2014). Buku Pintar Gadget Android. Jakarta: Niaga Swadaya.

Sari, P., dan Oktova, R., 2010, "Pemanfaatan Web Builder untuk perancangan media pembelajaran online tentang pengaruh rotasi bumi terhadap gerak bandul matematis," Berkala Fisika Indonesia, 2(2), 54-63.

Serway, R. A., \& Jewett, J. W. (2010). Fisika Untuk Sains Dan Teknik, Volume 3. Edisi ke-6. Diterjemahkan oleh: Chriswan Sungkono. Jakarta: Salemba Teknika. 